\title{
MORPHOLOGY OF THE ORAL CAVITY OF THE AFRICAN GIANT RAT (CRICETOMYS GAMBIANUS, WATERHOUSE)
}

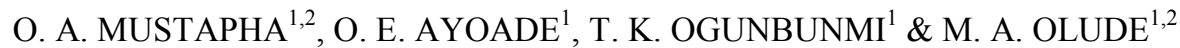 \\ ${ }^{1}$ Department of Veterinary Anatomy, College of Veterinary Medicine, Federal Uni- \\ versity of Agriculture, Abeokuta, Ogun State, Nigeria; ${ }^{2}$ Department of Veterinary \\ Anatomy, Faculty of Veterinary Medicine, University of Ibadan, Oyo State, Nigeria
}

\section{Summary}

Mustapha, O. A., O. E. Ayoade, T. K. Ogunbunmi \& M. A. Olude, 2015. Morphology of the oral cavity of the African giant rat (Cricetomys gambianus, Waterhouse). Bulg. J. Vet. Med., 18, No 1, 19-30.

Ten adult African giant rats (AGR), 5 males and 5 females, were used to determine the regional anatomy of their oral cavity. Body measurements were recorded. The oral cavity was accessed by disarticulating the temporo-mandibular joint and the gross morphology of the lips, palate, cheek pouch, teeth, tongue and major salivary glands were studied. Morphometric parameters of the cheek pouch, tongue and major glands were also determined. Histological features of the tongue were demonstrated after haematoxylin and eosin staining. The upper lip revealed a philtrum extending from the median septum of the nostrils and terminating at the oral fissure in a divergent triangle to expose the elongated incisors. The lower lip formed a smooth arch ventral to the upper lip. Average number of palatine ridges was 9. The tongue (mean weight of $3.80 \pm 0.08 \mathrm{~g}$ ) appeared spatula shaped. Main papillae were filiform and fungiform, with scattered vallate papillae on histology. The mean pouch capacity of males and females was $27.46 \pm 0.41 \mathrm{~mL}$ and $27.18 \pm 0.49 \mathrm{~mL}$ respectively while the dentition of the AGR was noted as 2(I1/1 C0/0 P0/0 M3/3) and showed typical rodent features. The major salivary glands (parotid and mandibular) were well developed. This work reports baseline research data on the anatomy of the AGR's oral cavity and will have usefulness in determining the adaptive features in this rodent to its diet, habitat and lifestyle.

Key words: African giant rat, cheek pouch, dentition, oral cavity, regional anatomy

\section{INTRODUCTION}

The African giant rat (AGR), Cricetomys gambianus, is a ubiquitous wild rodent of the suborder Myomorpha, adaptable to several environmental and diet conditions. Being an omnivore, it feeds on a variety of food items. AGR are found in Central Africa, in regions south of the Sahara de- sert as far south as Zululand; this includes countries such as Nigeria among others where they are often incorrectly called rabbits or Nigerian rabbits (Ajayi et al., 1978; Happlod, 1987). The animal is one of the most commonly consumed wildlife especially in Nigeria (Martin, 1985; 
Anadu et al., 1988) and had been recommended as a micro-livestock of Africa to supplement dietary animal protein intake because of its sheer body size, vast population and availability (FAO, 1970).

The head and body length of AGR ranges from $25-45 \mathrm{~cm}$ with scaly tails ranging from $36-46 \mathrm{~cm}$; measuring $75 \mathrm{~cm}$ from the nose to the tip of the tail, with the tail about $41 \mathrm{~cm}$ long. Adult females weigh between $1-1.5 \mathrm{~kg}$ and males have been known to reach nearly $3 \mathrm{~kg}$ and average basal metabolic rate of $71 \mathrm{~cm}^{3}$ oxygen/hour (Ajayi, 1977b; Nowak \& Paradisso, 1983; Ryan, 1989).

The oral cavity of the African giant rat contains vital organs such as the tongue (for taste), teeth (mastication and defence), cheek pouches (food storage and transport over long distances) and salivary glands (for lubrication). The cavity and its opening is the entrance into the alimentary canal of the digestive tract. The opening forms the junction between the integument and the digestive tract (Don, 2007). Among mammals, this junction forms the upper and lower lips, which extend as the mucocutaneous membrane into the initial portion of the alimentary canal. The cavity itself is typically asymmetrically shaped and composed of a narrow vestibule, which lies between the lips and cheek, the teeth and gingivae, and the relatively expansive buccal cavity, which extends internally between the oropharynx and the arches of the teeth (Hebel \& Stromberg, 1976).

The numerous functions of the oral cavity consist of taking in and breaking down of food both mechanically and chemically (Don, 2007). The palate (hard and soft) separates the nasal and the oral cavities.

The tongue is a muscular organ and consists of two muscle groups (intrinsic and extrinsic lingual muscles). The dorsal surface of the tongue is occupied by different types of projections called papillae which are grouped into mechanical and gustatory papillae, including lingual, filiform, fungiform and foliate papillae (Fish $\&$ Richter, 1946). The morphology and microscopic structure of the tongue have been investigated in goats (Igbokwe \& Okolie, 2009), cattle (Ebru et al., 2010), mice (Carrard et al., 2008), rats (Iwasaki et al., 1999; Nasr et al., 2012), primates (Kobayashi et al., 2004) and rabbits (Silva et al., 2002; Nonaka et al., 2008). The tongue of the Wistar rat is about $2.67 \pm 0.02 \mathrm{~cm}$ long from its bilaterally compressed tip to the base of the epiglottis and $0.58 \mathrm{~cm}, 0.66 \mathrm{~cm}$ and $1.2 \mathrm{~cm}$ wide at its apex, body and root with a deep median sulcus seen on the midline of the tongue (Ghazale \& Frangis, 2013). Nzalak et al. (2012) reported mean tongue weight and length of the AGR as $2.76 \pm 0.61 \mathrm{~g}$ and $4.62 \pm 0.14 \mathrm{~cm}$ respectively.

Cheek pouches are sac-like folds of skin on either side of the mouth playing an essential role in that they permit individuals to exploit seed resources efficiently throughout their home range and move those seeds to sites where the hoarder can exert a greater degree of control over them (Vander Wall et al., 1998). Thus knowledge of the cheek pouch capacity is essential to addressing general questions of AGR biology. The pouch capacity of the deer mice was reported as $0.45 \pm 0.11$ $\mathrm{mL}$, about $12-27 \%$ of that carried by similar-sized heteromyid rodents (Vander Wall et al., 1998)

Salivary glands are soft spongy tissues that secrete saliva and amylase. There are three pairs of salivary glands viz: parotid, mandibular and sublingual (Hebel \& Stromberg, 1976). Works have been documented on the submandibular glands of ferrets (Poddar \& Jacob, 1977), rats (Wa- 
tanabe et al., 1996), free-tailed bats (Nagato et al., 1998), chickens (Gargiulo et al., 1991), wallabies (Lentle et al., 2002), domestic cats (Mohammadpour, 2010), pigs (Zhou et al., 2010), and most recently, AGR (Ikpegbu et al., 2013). Nzalak et al. (2012) reported the mean weight of the parotid and mandibular salivary glands in the AGR as $0.81 \pm 0.03 \mathrm{~g}$ and $0.78 \pm 0.02 \mathrm{~g}$ respectively.

Although some authors have worked on some aspects of the digestive system of the AGR (Nzalak et al., 2010; 2012; Ikpegbu et al., 2013) as at the time of this report, no published comprehensive data exist on the morpho-anatomy of the oral cavity of the AGR.

\section{MATERIALS AND METHODS}

Ten adult African giant rats were used for the experiment: 5 males and 5 females. All the animals were obtained from local hunters in Abeokuta, Ogun State, SouthWestern Nigeria and examined for absence of facial deformities or abnormalities that may interfere with the research. Animals were housed using locally made cages $32 \mathrm{~cm}$ wide $\times 60 \mathrm{~cm}$ long $\times 21 \mathrm{~cm}$ high and had one half kept dark by means of a metal cap in order to satisfy their nocturnal behaviour, and to provide them with a dark sleeping chamber or nesting area. Food and water troughs containing rat pellets (Ladoke ${ }^{\circledR}$ type) were placed fixed to the wall of the cage at this end. The other end of the cage provided ventilation and light through screen wires. The rats were stabilised for 2 days before the experiment. The age of all rats was estimated according to Ajayi (1977b) who used weight estimates to classify the AGR as neonates $(0-70 \mathrm{~g})$, juveniles ( $>70 \mathrm{~g}$ but $<500 \mathrm{~g})$ and adult $(>500 \mathrm{~g})$.
All experiments were approved and carried out in accordance to guidelines of the animal use and ethics committee of the Federal University of Agriculture, Abeokuta. The animals were anaesthetised using chloroform in an inhalation chamber. Excess inhalation anaesthetic was administered before each dissection of animals to avoid spasms and expulsion of glandular products. Their body weights were recorded to the nearest kilogram. After anaesthesia, the oral cavity was accessed by disarticulating the temporo-mandibular joint. Normal saline was used in infiltrating the eviscerated tissues to maintain the normal body physiology.

Parameters were measured using Toledo Mettler balance ${ }^{\circledR}$, thread, ruler, grains and measuring cylinder. The tongue was dissected out with the portions of the apex and body taken for histology. Briefly, the tongue was post-fixed in $10 \%$ formalin for $72 \mathrm{~h}$ and subsequently, dehydrated through an ascending gradient of alcohol $(70 \%, 80 \%, 90 \%, 95 \%$ and $100 \%)$, each for one hour. The tissues were then cleared with xylene, embedded in paraffin wax at $58{ }^{\circ} \mathrm{C}$ and sectioned at $5 \mu \mathrm{m}$ with the microtome. These paraffin-embedded sections were mounted on glass slides and then routinely stained with haematoxylin and eosin. Slides were examined under light microscope (Leica ${ }^{\circledR}$ Model DME Microscope, Model: 13595XXX, Leica Microsystems) and images of the tongue epithelia histomorphology were captured with Canon ${ }^{\circledR}$ Power shot S70 camera (PC 1087, No. 033102132). All data were obtained using Student Package for Social Sciences (v. 16) and results were expressed as mean \pm standard error of mean and analysed with the Student $t$ test.

The following morphometric parameters were defined - head length: length from the tip of the nose to the occipital 
bone (nuchal crest) $(\mathrm{cm})$; body length: length from the first cervical (atlas) to the last sacral bone $(\mathrm{cm})$; nose-rump length: measured from the tip of the nose to the last sacral bone about the sacrococcygeal joint $(\mathrm{cm})$; tail length: length from the caudal part of the last sacral bone and the cranial tip of the first coccygeal bone to the caudal tip of the last coccygeal bone $(\mathrm{cm})$; body weight: weight in the nearest kilogram ( $\mathrm{kg}$ ) of live animals; pouch capacity: estimated by filling the pouch with fine grains and then measuring the volume with a measuring cylinder $(\mathrm{mL})$.

\section{RESULTS}

The mean body weights of males and females were $0.89 \pm 0.08 \mathrm{~kg}$ and $0.78 \pm 0.11$ $\mathrm{kg}$ respectively, while the overall mean was $0.83 \pm 0.07 \mathrm{~kg}$ (Table 1). The mean body lengths of the males and females were $66.54 \pm 1.23 \mathrm{~cm}$ and $67.84 \pm 1.81 \mathrm{~cm}$ respectively, while the overall mean was $67.20 \pm 1.05 \mathrm{~cm}$. The mean of the tail lengths were $35.00 \pm 0.83 \mathrm{~cm}$ and $35.42 \pm$ $1.41 \mathrm{~cm}$ for the males and females respectively. Males were heavier while females were relatively longer. In this study, there were no statistically significant differences in all measured parameters between both sexes - thus authors report the absence of sexual dimorphism.

The upper lip (labium maxillare) was cleaved mid-sagitally by deep hairless philtrum rostrally. This groove continued as a deep pocket around the neck of the upper incisors and caudally as the groove directed toward the roof of the oral cavity (proper). Hairy upper lips covered the upper incisors laterally so that only the tips were visible. The transition from the hairy outer surface to oral mucosa was along the edge of a fold which ran rostromedially from the commissure of the mouth as far as the distant contact surface of the incisor tooth. Between the folds of each side was located the incisive papilla - a three-cornered pyramid with a height of $1.5 \pm 0.05 \mathrm{~mm}$ and close to its rounded tip laid the slit-like orifices of the incisive duct.

The part of the hard palate (palatum durum), between the incisive papilla and the mesial surface of the first molar tooth contained two transversely running, $1 \mathrm{~mm}$ high palatine ridge - rugae palatinae. Between the two molar arcades another five or six W-shaped lower rugae crossed the hard palate, covered with a heavily cornified epithelium and their caudal edges bore short cornified papillae. The transition between the hard to soft palate was

Table 1. Morphometric parameters of body and oral cavity in adult African giant rats. Data are given as mean \pm SEM

\begin{tabular}{lrrr}
\hline Parameters & Male $(\mathrm{n}=5)$ & Female $(\mathrm{n}=5)$ & Overall $(\mathrm{n}=10)$ \\
\hline Body weight $(\mathrm{kg})$ & $0.89 \pm 0.08$ & $0.78 \pm 0.11$ & $0.83 \pm 0.07$ \\
Nose-rump length $(\mathrm{cm})$ & $66.54 \pm 1.23$ & $67.84 \pm 1.81$ & $67.20 \pm 1.05$ \\
Tail length $(\mathrm{cm})$ & $35.00 \pm 0.83$ & $35.42 \pm 1.41$ & $35.31 \pm 0.78$ \\
Number of rugae & $8.80 \pm 0.20$ & $8.80 \pm 0.20$ & $8.80 \pm 0.13$ \\
Tongue length $(\mathrm{cm})$ & $5.20 \pm 0.42$ & $4.30 \pm 0.28$ & $4.75 \pm 0.28$ \\
Tongue width $(\mathrm{cm})$ & $1.76 \pm 0.11$ & $1.36 \pm 0.16$ & $1.56 \pm 0.11$ \\
Mid tongue width $(\mathrm{cm})$ & $1.14 \pm 0.08$ & $0.92 \pm 0.06$ & $1.75 \pm 0.70$ \\
Pouch capacity $(\mathrm{mL})$ & $27.46 \pm 0.41$ & $27.18 \pm 0.49$ & $27.32 \pm 0.30$ \\
\hline
\end{tabular}




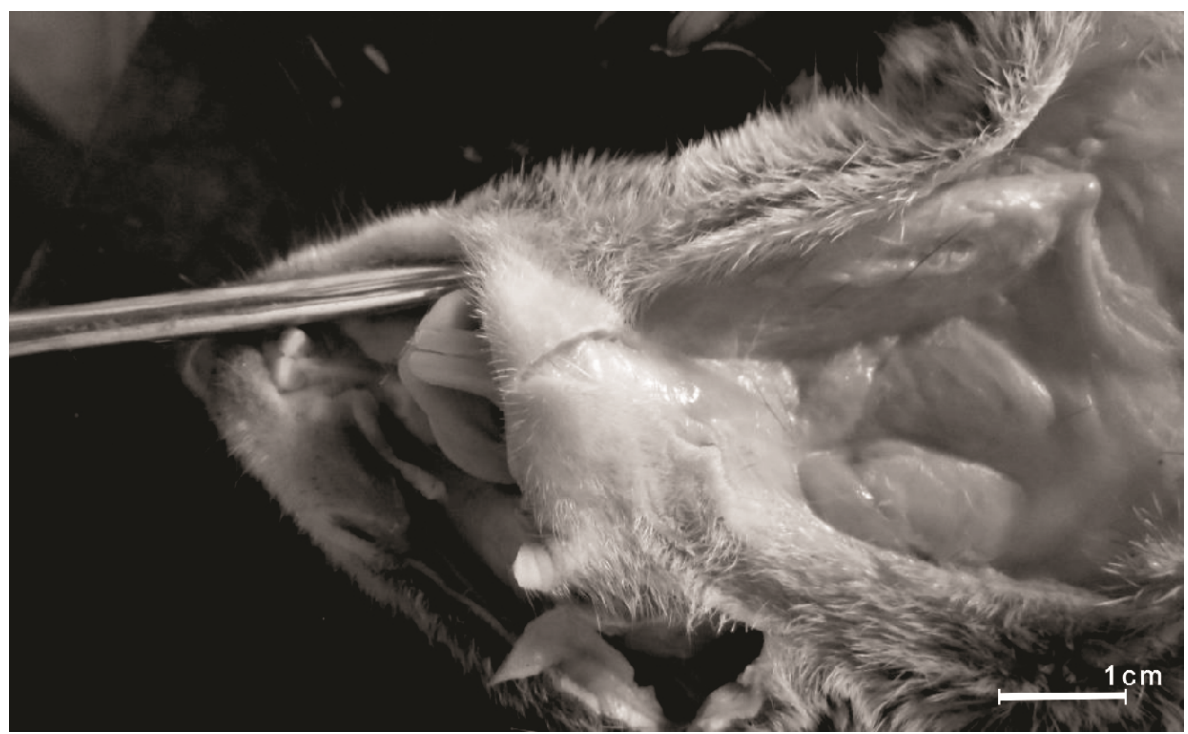

Fig. 1. Ventral view of the head and neck of the AGR (with skin reflected and forceps inserted through the mouth to show the extent of the cheek pouch).

marked by a pale line in the mucous membrane. The soft palate (palatum molle), was formed by a caudally narrowing septum of $0.5 \pm 0.04 \mathrm{~mm}$ thickness, tightly attached to the wall of the pharynx. The ventral surface of the soft palate showed fine openings of glandular ducts of the submucous palatine gland. A median strip of the soft palate displayed numerous low papillae (diameter $0.25 \pm 0.02 \mathrm{~mm}$ ) and transverse folds near the caudal rim. The average number of ridges on the hard pallate was approximately 9.

The mean pouch capacity of males was $27.46 \pm 0.41 \mathrm{~mL}$ while that of females was $27.32 \pm 0.30 \mathrm{~mL}$. The cheek pouches consisted grossly of a buccal and a sublingual part. The buccal part lined the mucosa of the cheeks medially and the medial face of the masseter muscle. The sublingual part, an extension of the buccal part, covers the ventral part of the mandible, masseter and the mandibular lymph nodes to join the pouch of the other side and inserted on the pectoral muscles and the ventral sternum (Fig. 1). Thus, males have a relatively higher tendency of storing more food in their pouches compared to females.

The dentition of the African giant rat showed the typical rodent features with two incisors on each jaw; a wide diastema between the incisors and molars; three cheek teeth per side in upper and lower jaws. Dental formula was constant in all rats used in this study and given as: $2[\mathbf{I} 1 / 1$ $\mathbf{C} 0 / 0 \mathbf{P} 0 / 0 \mathrm{M} 3 / 3]=16$. There were large vacancies in the jaws but the vacancy in the upper jaw was greater than that in the lower jaw. The average distance of the diastema in the upper jaw was $2.1 \pm$ $0.02 \mathrm{~cm}$ while that in the lower jaw was $1.10 \pm 0.03 \mathrm{~cm}$. Mean diastemal distance was not statistically significant different between sexes.

The mean weight of the tongue was $3.80 \pm 0.08 \mathrm{~g}$. The tongue width was about one-third of its length, with overall mean tongue length of $4.75 \pm 0.28 \mathrm{~cm}$ and overall mean tongue width of $1.56 \pm 0.11 \mathrm{~cm}$. 

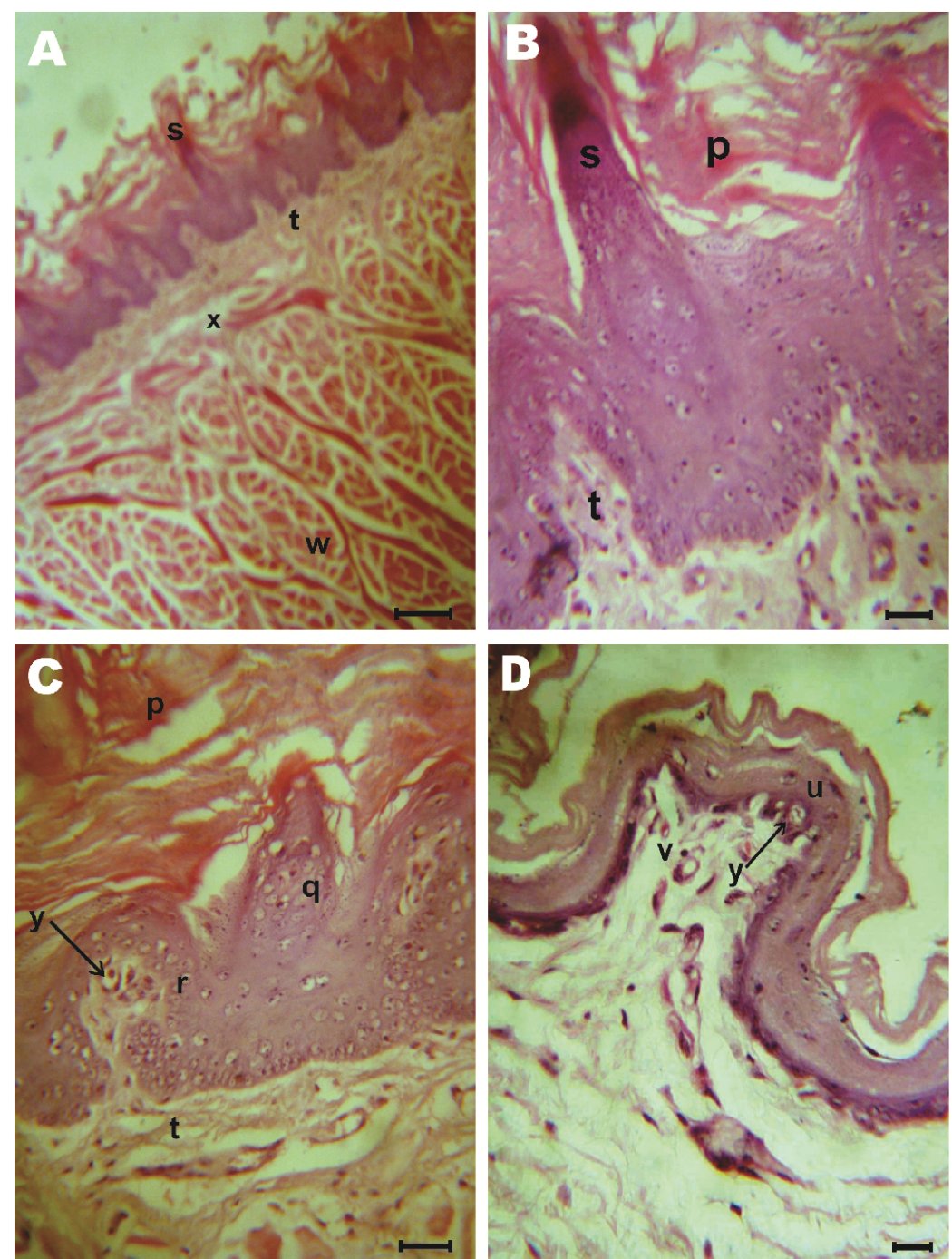

Fig. 2. Tongue (H \& E stain). A. Tongue apex with keratinised stratified squamous epithelium with numerous lingual papillae, prominent lamina propria $(\mathrm{t})$ and a thin tunica submucosa of connective tissue (x) lying between the mucosa and skeletal muscles (w), bar=100 $\mu \mathrm{m}$; B. Tongue apex: filiform papillae (s) are the most numerous lingual papillae. They are slender, projected above the lingual surface. Keratinised stratified squamous epithelium covers the papillae and a lamina propria $(t)$ underlies the mucosa, bar $=50 \mu \mathrm{m} ; \mathbf{C}$. conical (q) and fungiform (r) papillae seen on the body of the tongue. The conical papillae are larger than the filiform ones. The shape of the fungiform papillae is mushroom-like with connective tissue forming its core and a taste bud (y) stained on this papilla, bar=50 $\mu \mathrm{m}$; D. Vallate papillae (u) are located on the dorsum of the tongue: large, flattened structures extending slightly above the lingual surface. Stratified squamous epithelium covered the surface and taste buds (y) are frequently present in the epithelium. Connective tissue (v) seen at the core of the papilla, bar $=50 \mu \mathrm{m}$. 
Grossly, from its dorso-ventrally compressed tip to the base of the epiglottis, the tongue was divided into three parts: the rostral part (apex), the caudal part (root) and the medially compressed part (body). It presented a spatula shaped apex - broader cranially and narrowed down caudally until about the caudal one-third from which it had a uniform width; at which point, a raised dorsal prominence (torus linguae) was observed on the dorsum. The cranial two-thirds of the dorsum bore a median lingual sulcus and the root was embedded in the hyoid bone. The epithelial lining of the tongue was keratinised stratified squamous epithelium (Fig. 2).

Lingual papillae i.e. the mechanical and gustatory papillae were abundant on the dorsal surface of the tongue. Filiform papillae were well developed, slender, projected above the surface of the tongue and covered the rostral part of the tongue. Keratinised stratified squamous epithelium covered a core of the connective tissue within each papilla (Fig. 2A and B). The caudal end of the dorsal surface was free of mechanical papillae. All papillae appeared grossly as pale dots. Fungiform papillae were seen between the apex and the dorsal prominence of the tongue irregularly interspersed among the filiform papillae. They did not extend far above the surface of the epithelium and almost always contained taste buds (Fig. 2C). Their connective tissue core formed finger-like secondary processes and bore a common conical cap of cornified epithelium. The vallate papillae were sparsely distributed on the dorsum of the tongue just rostral to the root. They appeared as large flattened structures that extend slightly above the tongue surface. Stratified squamous epithelium covered the surface and taste buds were noticed in the epithelial layer around each papillae (Fig.
2D). Taste buds were also found at sites independent of the special gustatory organs within the oral cavity and in the terminal parts of excretory ducts of salivary glands.

The major glands i.e. the parotid, mandibular and sublingual glands were paired and well developed. The distinct oval shaped, lobed flat parotid gland (weight $0.33 \pm 0.02 \mathrm{~g}$; length $1.7 \pm 0.09 \mathrm{~cm}$ ) extended along the caudal border of the mandible towards the ventral aspect of the larynx and extended caudally toward the clavicle. The parotid duct, formed by the fusion of the excretory ducts from each lobe of the parotid gland, ran rostrally into the oral cavity at the rostral border of the masseter muscle and opened opposite the upper second molar. The dorso-ventrally compressed mandibular gland (weight $1.85 \pm 0.05 \mathrm{~g}$; length $4.8 \pm 0.20 \mathrm{~cm}$ ) lied in the ventral cervical region towards the thoracic inlet bordering the mandibular lymph nodes rostrally and its counterpart medially. The sublingual gland (weight $0.25 \pm 0.01 \mathrm{~g}$; length $1 \pm 0.096 \mathrm{~cm}$ ) was lens shaped, tightly attached to the mandibular gland with a darker colour. Both the mandibular and sublingual excretory ducts ran rostrally along the medial surface of the mandible. They turned dorsally and opened separately on the rostral aspect of the sublingual caruncle close to the mandibular symphysis.

The relative glandular mass of the parotid, mandibular and sublingual salivary gands accounted for $0.04 \%, 0.22 \%$ and $0.03 \%$ of the AGR body weight.

\section{DISCUSSION}

The mean body weight of the African giant rat $(0.83 \pm 0.07 \mathrm{~kg})$ in this study was larger when compared to other rodents such as the vole, ground squirrel, desert 
hamster, striped hamster, Mongolian gerbil, whose mean body weights were reported as $0.03 \mathrm{~kg}, 0.15 \mathrm{~kg}, 0.02 \mathrm{~kg}, 0.02$ $\mathrm{kg}$ and $0.05 \mathrm{~kg}$ respectively (Wang et al., 2002). It is however smaller than the greater cane rat (Adu \& Yeboah, 2003; Byanet et al., 2008); thus explaining why the AGR is ranked as the continent's second most hunted microlivestock, after the cane rat (Asibey, 1974; Olude et al., 2013).

Feed conversion is also likely to be a responsible factor for the body mass index apart from natural morphologies. Large indices of the masticatory apparatus and oral cavity indicate a larger surface area and naturally larger jaw muscles and larger absolute gape which are essential in feed conversion (Greaves, 1983). The comparatively larger body weight of males as against females in all the samples studied is in tandem to the finding of Dzenda et al., (2011) who found the live weight of male AGR to be higher than females irrespective of the season. It has also been postulated that the social behaviour of the rats may contribute to the size difference. Males are usually solitary while female were found in colonies with their young or the burden of pregnancy; implying a higher competition for feed amongst females than males (Olude, 2009)

The relatively longer and wider apical tongue $(4.75 \pm 0.28 \mathrm{~cm}, 1.56 \pm 0.11 \mathrm{~cm})$ in this study, compared to that of the Wistar rat $(2.6 \mathrm{~cm}, 0.8 \mathrm{~cm})$ can be strongly linked to relative differences in size (Hebel \& Stromberg, 1976). The tongue of the African giant rat resembles that of the spatula shaped equine tongue (Sisson \& Grossman, 1953) while the middle attenuation represents the compression of the molar teeth. The cornified stratified squamous epithelium as well as the filiform and fun- giform papillae of the tongue protects it from damage during mastication. This enables this rodent to take advantage of coarse foods with ease. The relatively low number of vallate papillae is a pointer that these rats engage meals with little taste discrimination (Hebel \& Stromberg, 1976).

Cheek pouches are adaptive features for storage and transportation of large amount of feed for hoarding (Ajayi, 1977a). This implies that the velocity of acquiring food is higher in rodents with the pouches and can serve as an advantage in times of scarcity. However, the relationship of the pouch to structures such as the pectoral muscle, salivary glands presents a risk factor in cases where sharp objects are unknowingly picked up as bulk food. Pathologies arising from such anatomical proximities in ruminants have been well documented as seen in traumatic reticulopericarditis/ reticuloperitonitis (Akkoç, 2007; Constable, 2012). This could predispose to suggested pathological conditions such as traumatic myositis or traumatic adenitis in the AGR. However, no known case of conditions arising from this anatomical relationship of the AGR has been reported.

The cheek pouches play an essential role in the economy of these rodents in that the pouches permit individuals to exploit seed resources efficiently throughout their home range and move those seeds to sites where the hoarder can exert a greater degree of control over them (Vander Wall et al., 1998). Interestingly, AGRs find almost as much value in the act of carrying as much as the act of hoarding food (Ajayi, 1977a; Ajayi et al., 1978). This results in confusing hoarding patterns when food is plentiful in any season. This adaptive feature however, allows Gambian rats to transport an ex- 
traordinary amount of material in a short period of time. Some studies have shown them to transport up to $3 \mathrm{~kg}$ in two and half hours (Ajayi, 1977a; Ajayi et al., 1978).

The mean pouch capacity and the mean pouch capacity to mean body weight ratio (MPC/MBW) of the AGR $27.32 \pm 0.30 \mathrm{~mL}$ and $0.033 \mathrm{~mL} / \mathrm{g}$ body weight were significantly higher as compared with those of the deer mice: $0.45 \pm$ $0.11 \mathrm{~mL}$ and $0.019 \mathrm{~mL} / \mathrm{g}$ body weight respectively (Vander Wall \& Longland, 1999). The two most important factors governing cheek pouch capacity - body mass and the density of the preferred food - have been described (Morton et al., 1980). Thus these factors probably accounts for the higher $\mathrm{MPC} / \mathrm{MBW}$ ratio in the AGR ( $>150 \%$ of the deer mice).

Cheek pouches of deer mice, about $12-27 \%$ of that carried by similar-sized heteromyid rodents, give them the capacity to carry 3-5 times more food than unspecialised mice. This presumably increases efficiency of deer mice in exploiting small, particulate food items that are patchily distributed (Vander Wall \& Longland, 1999).

Owning to the bigger size of the salivary glands of the AGR compared to those of the Wistar rat (Hebel \& Stromberg, 1976), the AGR is thus been proposed as a suitable research model for studying the pathogenesis of salivary gland tumours (Batsakis et al., 1983), and the use of salivary gland adiposity to correlate the level of liver cirrhosis in alcoholic patients (Scott et al., 1988). This lends credence to the growing ambition to use the AGR as a substitute for the Wistar rat in research (Dipeolu et al., 1981; Olayemi et al., 2001).

The macroscopic studies of the oral cavity offer insight into the adaptive morphology and mechanism by which the
AGR utilises and manipulates its feed for proper feed conversion to body mass. The findings reported in thiis paper therefore, contribute to the body of knowledge in the understanding of the anatomy of this rodent.

\section{REFERENCES}

Adu, E. K. \& S. Yeboah, 2003. On the use of perineal stain as an index of sexual maturity and breeding condition in the male greater cane rat (Thryonomys swinderianus, Temminck). Tropical Animal Health and Production, 35, 433-439.

Ajayi, S. S., 1977a. Field observations on the African giant rat (Cricetomys gambianus) in Southern Nigeria. East African Wildlife Journal, 15, 191-198.

Ajayi, S. S., 1977b. Live and carcass weights of giant rat (Cricetomys gambianus) and domestic rabbit (Oryctalagus cuniculus). East African Wildlife Journal, 15, 223 228.

Ajayi, S. S., O. Tewe \& E. Faturoti, 1978. Behavioural changes in African giant rat (Cricetomys gambianus Waterhouse) under domestication. East African Wildlife Journal, 16, 137-143.

Akkoç, A., 2007. Traumatic reticulopericarditis in a Saanen goat. Turkish Journal of Veterinary and Animal Science, 31, 283285.

Anadu, P. A., P. O. Elamah \& J. F. Oates, 1988. The bushmeat trade in SouthWestern Nigeria: A case study. Human Ecology, 16, 199-208.

Asibey, E. O. A., 1974. Wildlife as source of protein in Africa: South of the Sahara. Biological Conservation, 6, 32-39.

Batsakis, J. G., B. Kraemer \& J. J. Sciubba, 1983. The pathology of head and neck tumors: the myoepithelial cell and its participation in salivary gland neoplasia, Part 17. Head \& Neck Surgery, 5, 222-233.

Byanet, O., S. O. Salami, M. N. Ali, J. Imam, S. M. Maidawa, A. D. Umosen, C. 
Alphonsus \& J. O. Nzalak, 2008. The macro-anatomy of the stomach of the wild African pouched rat (Cricetomys gambianus). Sahel Journal of Veterinary Sciences, 9, 69-72.

Carrard, V. C., A. S. Pires \& C. M. Badauy, 2008. Effects of aging on mouse tongue epithelium focusing on cell proliferation rate and morphological aspects, Bulletin of the Tokyo Dental College, 49, 199-205.

Constable, P. D., 2012. Traumatic reticuloperitonitis. In: The Merck Veterinary Manual, $8^{\text {th }}$ edn, Merck and Co., Inc. WhiteHouse station, New Jersey, U.S.A. http://www. merckmanuals.com/vet/digestive_system/ diseases_of the_ruminant_forestomach/ traumatic_reticuloperitonitis.html (2 June 2014, date last accessed).

Dipeolu, O. O., O. A. Akinboade \& F. Ogunji, 1981. Observation of the African giant rat (Cricetomys gambianus Waterhouse) experimentally infected with salivarian trypanosomes. Bulletin of Animal Health and Production in Africa, 29, 393-397.

Don, A. S., 2007. Textbook of Veterinary Histology, $1^{\text {st }}$ edn, W. B. Saunders Company, U.S.A.

Dzenda, T., J. O. Ayo, C. A. M. Lakpini \& A. B. Adelaiye, 2011. Seasonal and sex variations in live weights of captive African giant rats (Cricetomys gambianus, Waterhouse) in the Northern Guinea savannah zone of Nigeria. International Journal of Zoological Research, 7, 49-58.

Ebru, K. S., K. H. Melek \& S. H. Ismail, 2010. Characteristics of dorsal lingual papillae of Zavot cattle. Journal of Animal and Veterinary Advances, 9, 123-130.

FAO, 1970. Wildlife Management in Nigeria. FAO SF/MIR 12 Technical Report No. 11970.

Fish, H. \& C. P. Richter, 1946. Comparative number of fungiform and foliate papillae on tongues of domestic and wild Norway rats. Proceedings of the Society for Experimental Biology and Medicine, 63 , 352-355.
Gargiulo, A. M., S. Lorvik, P. Ceccarelli \& V. Pedini, 1991. Histological and histochemical studies on the chicken lingual glands. British Poultry Science, 32, 693-702.

Ghazale, C. \& G. Frangis, 2013. Macroscopic and microscopic study of tongue in wistar rats. Indian Journal of Fundamental and Applied Life Sciences, 3, 39-44.

Greaves, W. S., 1983. A functional analysis of carnassials biting. Biological Journal of Linnean Society, 20, 353-363.

Happold, D. C. D., 1987. The Mammals of Nigeria. Clarendon Press. Oxford.

Hebel, R. \& Stromberg M., 1976. Anatomy of the Laboratory Rat. The Wilkins and Wilkins Company, pp. 43-46.

Igbokwe, C. O. \& C. Okolie, 2009. The Morphological observations of some lingual papillae in the prenatal and prepuberal stages of Red Sokoto goats (Capra hircus). International Journal of Morphology, 27, 145-150.

Ikpegbu, E., U. C. Nlebedum, O. Nnadozie \& I. O. Agbakwuru, 2013. Microscopic study of the submandibular salivary gland of adult African giant pouched rat (Cricetomys gambianus, Waterhouse -1840). Iraqi Journal of Veterinary Science, 27, 85-89.

Iwasaki, S., H. Yoshizawa \& I. Kawahara, 1999. Ultrastructure study of the relationship between the morphogenesis of filiform papillae and the keratinization of the lingual epithelium in the rat. Journal of Anatomy, 195, 27-38.

Kobayashi, K., M. Kumakura, K. Yoshimura \& M. Takahashi, J. H. Zeng, I. Kageyama, K. Kobayashi \& N. Hama, 2004. Comparative morphological studies on the stereo structure of the lingual papillae of selected primates using scanning electron microscopy. Annals of Anatomy, 186, 525-530.

Lentle, R. G., I. D. Hume, M. S. Kennedy, K. J. Stafford, M. A. Potter, B. P. Springett \& S. Haslett, 2002. The histology and morphometrics of the major salivary glands of four species of wallabies (Marsupialia: Macropodiae) from Kawau Is- 
land, New Zealand. Journal of Zoology, 257, 403-410.

Martin, G. H. G., 1985. Carcass composition and palatability of some wild animals commonly used as food. World Animal Review, 53, 40-53.

Mohammadpour, A. A., 2010. Anatomical and histological study of molar salivary gland in domestic cat. Iranian Journal of Veterinary Research, 11, 164-167.

Morton, S. R., D. S. Hinds \& R. E. MacMillen, 1980. Cheek pouch capacity in heteromyid rodents. Oecologia (Berlin), 46, 143-146.

Nagato, T. B. Tandler \& J. P. Carleton, 1998. Ultrastructure of the binary parotid glands in the free-tailed bat, Tadarida thersites. II. Accessory parotid gland. The Anatomical Record, 251, 122-135.

Nasr, E. S., A. M. Gamal \& E. H. Elsheikh, 2012. Light and scanning electron microscopic study of the dorsal lingual papillae of the rat Arvicanthis niloticus (Muridae, Rodentia). The Journal of American Science, 8, 619-627.

Nonaka, K., J. Zheng \& K. Kobayashi, 2008. Comparative morphological study on the lingual papillae and their connective tissue cores in rabbits. Okajimas Folia Anatomica Japonica, 85, 57-66.

Nowak, R. M. \& J. L. Paradisso, 1983. Walker's Mammal of the World, $4^{\text {th }}$ edn, Johns Hopkins University Press, Baltimore, pp. 569-1362.

Nzalak, J. O., B. I. Onyeanusi \& S. O. Salami, 2012. Macroscopic study of the digestive system of the African giant rat (AGR) (Cricetomys gambianus Waterhouse, 1840). European Journal of Anatomy, 16, 113-118.

Nzalak, J. O., B. I. Onyeanusi, S. A. Ojo, A. A. Voh \& C. S. Ibe, 2010. Gross anatomical, histological and histochemical studies of the esophagus of the African giant rat (AGR) (Cricetomys gambianus Waterhouse, 1840). Journal of Veterinary Anatomy, 3, 55-64.
Olayemi, F. O., O. A. Oke, J. O. Oyewale \& A. O. Ogunsanmi, 2001. The effect of season on the blood profile of the African giant rat (Cricetomys gambianus, Waterhouse). Israel Journal of Veterinary Medicine, 56, 147-150.

Olude, M. A., O. A. Mustapha, T. K. Ogunbunmi \& J. O. Olopade, 2013. The vertebral column, ribs and sternum of the African Giant Rat (Cricetomys gambianus Waterhouse). The Scientific World Journal, http://www.hindawi.com/journals/ tswj/2013/973537/ (2 June 2014 date last accessed).

Olude, M. A., 2009. Craniometric measurements of the skull of the African giant rat (Cricetomys gambianus, Waterhouse). Master's dissertation, Department of Veterinary Anatomy, University of Ibadan, Nigeria.

Poddar, S. \& S. Jacob, 1977. Gross and microscopic anatomy of the major salivary glands of the ferret. Acta Anatomica (Basel), 98, 434-443.

Ryan, J., 1989. Evolution of cheek pouches in African pouch rats (Rodentia: Cricetomyinae). Journal of Mammalogy, 70, 267274.

Scott, J., J. Burns \& E. A. Flower, 1988. Histological analysis of parotid and submandibular glands in chronic alcohol abuse: A necropsy study. Journal of Clinical Pathology, 41, 837-840.

Silva, M. C. P., I. Watanabe \& M. C. Kronka, 2002. Three-dimensional architecture of the connective tissue core and surface structure of the lingual papillae in the rabbit. Histology and Histopathology, 17, 455-461.

Sisson, S. \& J. D. Grossman, 1953. The digestive system. In: The Anatomy of the Domestic Animals, $4^{\text {th }}$ edn, W. B. Saunders Company, Philadelphia and London, pp. 392.

Vander Wall, S. B. \& W. S. Longland, 1999. Cheek pouch capacities and loading rates of deer mice (Peromyscus maniculatus). Great Basin Naturalist, 59, 278-280. 
Morphology of the oral cavity of the African giant rat (Cricetomys gambianus, Waterhouse)

Vander Wall, S. B., W. S. Longland, S. Pyare \& J. A. Veech, 1998. Cheek pouch capacities and loading rates of heteromyid rodents. Oecologia, 113, 21-28.

Wang, D. H., Y. X. Pei, J. C. Yang \& Z. Wang, 2002. Digestive tract morphology and food habits in six species of rodents. Folia Zoologica, 52, 51-55.

Watanabe, L., H. Seguchi, T. Oxada, T. Kobayashi, Q. S. Jin \& X. D. Jiang, 1996. Fine structure of the acinar and duct cell component in the parotid and submandibular glands of the rat: A TEM, SEM and HRSEM study. Histology and Histopathology, 11, 103-110.

Zhou, J., H. Wang, G. Yang, X. Wang, Y. Sun, T. Song, C. Zhang \& S. Wang, 2010. Histological and ultrastructural characterization of developing miniature pig salivary glands. Anatomical Record (Hoboken), 293, 1227-1239.
Paper received 09.10.2013; accepted for publication 20.02.2014

\section{Correspondence:}

Dr Oluwaseun A. Mustapha

Vertebrate Morphology, Environmental

Toxicology and Neuroscience Unit

Department of Veterinary Anatomy,

College of Veterinary Medicine,

Federal University of Agriculture, Abeokuta

Ogun State, Nigeria

Phone: +234803 5915275

e-mail: drmustyplato@yahoo.co.uk 